\title{
A Study on Application of Polyvinylchloride (PVC) Waste and Sawdust in Wood-Plastic Composite
}

\author{
Ali Akbar Enayati ${ }^{1 *}$, Fatemeh Ramezanian Sani ${ }^{2}$ and Fatemeh Kavei ${ }^{2}$ \\ ${ }^{1}$ Prof. of Wood Composites Panel Technology, University of Tehran, Iran \\ ${ }^{2} \mathrm{MSc}$ in wood Science and Technology, University of Tehran, Iran
}

ISSN: 2576-8840

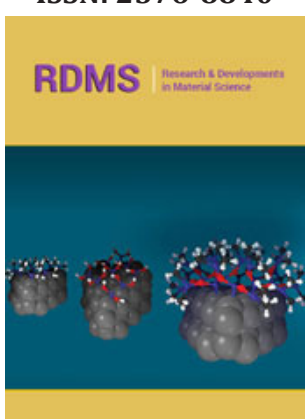

*Corresponding author: Ali Akbar Enayati, Prof of Wood Composites Panel Technology, University of Tehran, Iran

Submission: 啙April 02, 2021

Published: 眥April 27, 2021

Volume 15 - Issue 2

How to cite this article: Ali Akbar Enayati, Fatemeh Ramezanian Sani, Fatemeh Kavei. A Study on Application of Polyvinylchloride (PVC) Waste and Sawdust in WoodPlastic Composite. Res Dev Material Sci. 15(2). RDMS.000856. 2021. DOI: $10.31031 / R D M S .2021 .15 .000856$

Copyright@ Ali Akbar Enayati. This article is distributed under the terms of the Creative Commons Attribution 4.0 International License, which permits unrestricted use and redistribution provided that the original author and source are credited.

\begin{abstract}
The present study is focused on the possibility of use of PVC wastes and sawdust (dividing cut and edging of MDF panels) in WPC production. Variables included mixing ratio in three levels (45/55, 50/50 and $60 / 40$ ), as well as press time of $8,10,12$ minutes. Panels were compressed in a molde and physical and mechanical properties of panels including bending strength, tensile strength, bending and tensile modulus, impact strength and Thickness Swelling (TS) were measured. The results showed that the mechanical properties of panels were significantly higher when the PVC/Sawdust ratio was 50:50. Thicknesses swelling after 24 hours as well as long term holding decreased with the increase in PVC / sawdust ratio. In addition, the physical and mechanical properties of composite have been significantly affected by press time. It was concluded that the panel made of 50\% PVC combined with 50\% sawdust pressed for 8 minutes exhibited suitable properties for most applications.
\end{abstract}

Keywords: PVC; Wood-plastic composite; MDF; Press time; Physical and mechanical properties

\section{Introduction}

Increasing the wood composite products and the plastic wastes amount in one hand and their environmental unfavorable effects on the other hand, forced researchers to present solutions. One of the most successful strategies to solve both problems is to use them in wood-plastic composites production, which is use currently in many countries [1].

Wood plastic composites refer to all composites consisting of wood and thermosetting or thermoplastic materials. Nowadays more attention is allocated to thermoplastic composites, and wood-PVC composites are one of the commonest. However, the type of plastic in composites depends on its inherent properties, the type of product and its end-use, the accessibility of the plastic, and expenses [1]. Production of wood plastic composites has economical advantages because of variety in raw materials. Moreover, wood plastic composites have better natural durability in comparison with solid wood [2]. It was reported that at a dosage of 35\% (weight percent) of soy straw powder and $6 \%$ nano-clay particles addition, the strength properties of composites except tensile and flexural modulus as well as the impact strength reduced. At the higher amount of the nano-clay, the flexural strength and tensile strength decreased and tensile and flexural modulus as well as the impact strength improved [3].

Tasouji et al. [1] studied the physical and mechanical properties of wood-plastic composites produced from wheat and rice straw particles, nano-clay, polypropylene and MAPP. The panels made of rice straw showed better results compare to those of wheat straw due to their high amount of silica and its compatibility with nano-clay. Nourbakhsh [4] has reported that agricultural residue fibers (i.e., corn stalk, reed stalk, and oilseed stalk) materials are attractive reinforcements from the standpoint of mechanical properties. Overall trend showed that with the addition of agricultural residue fibers, tensile and flexural properties of the composites are significantly enhanced. Oilseed fibers showed superior mechanical properties due to their high aspect ratio and chemical characteristics. Aliyegebenoma et al. [5] focused on the modeling and production of the injection molded PolyvinylchlorideSawdust (PVC-sawdust) composite. The results for PVC-Sawdust composite showed that the tensile strength, proof stress, flexural strength and flexural modulus were maximized at barrel temperature of $224.65{ }^{\circ} \mathrm{C}$ and polymer level of $61.46 \%$ respectively the coefficient of determination (R2) obtained ranged from 0.9213 (92.13\%) to $0.981(98.10 \%)$. 
Ahmad [6] tried to provide more insight into the optimum injection temperature used for the production of PE crates. The results revealed that producing the crates at a temperature range of $260-280{ }^{\circ} \mathrm{C}$ gives the best rheological and mechanical result. The lowest drop in thermal stability was observed for the crates produced at this temperature range. Wechesler et al. [7] investigated the effect of radiant pine wood fibers and its powder with mesh 10 to 100, at 60 and $80 \%$ levels in the manufacturing of plastic wood composites using polypropylene thermoplastic. The physical and chemical properties of the samples were improved by adding four chemicals to the boards. Plastic wood composites that were made by wood powder had lower mechanical strengths than wood-plastic composites made by wood fibers. Chaharmahali et al. [8] using two methods including melt blend and dry blend to produce Wood-Plastic composites Panels from high density polyethylene (as resin) and particleboard waste (as natural fiber). Mechanical properties of samples made with dry blend method were generally higher than those of samples made with melt blend method for all corresponding formulations. Ghasemi et al. [9] examined the effect of wood particle size $(100,250$, and $400 \mu \mathrm{m})$ on the physical mechanical properties of WPC such as tensile properties, Heat Distortion Temperature (HDT), Melt Flow Index (MFI) and notched Izod impact resistance as well as the rheological behaviors as function of wood particle size. The data showed that an increase in wood particle size increased the tensile modulus and MFI while there was no considerable change in the elongation-atbreak. The results also indicated that the impact resistance and tensile strength increased as the particle size increasing. (HDT) was independent of variation of wood particle size.

Shakeri et al. [10] fabricated cellolusic fibers-polymer composite using recycled polystyrene and waste newspaper. It was found that the highest tensile strength and impact strength was obtained in sample which contained $78 \%$ recycled polystyrene, 20\% paper fibers and 2\% Maleic Anhydrided (MA). Stark [11] used Dumardon's extruder to measure the effect of size and distribution of wood particles on the physical and mechanical properties of wood-plastic polymers at $190{ }^{\circ} \mathrm{C}$. According to the result, the smaller the particles size, the better mechanical properties (e.g., higher modulus and tensile strength). In addition, the best particle size for a good process and proper properties was 100 mesh. Little or no study is carried out on a mixture of sawdust and PVC wastes as two important raw materials in flat pressed WPCs. This research aimed to study the possibility of producing wood-plastic panels using PVC and sawdust wastes and evaluation their physical and mechanical properties.

\section{Materials and Methods}

PVC polymer wastes was purchased from plastic materials factories and sawdust particles (dividing cut and edging of MDF panels) from kitchen cabinet industries. The PVC material had a density of $1.30-1.45 \mathrm{~g} / \mathrm{cm}^{3}$, water absorption of $0.04-0.4 \%$, specific heat of $0.9 \mathrm{~kJ}$, thermal conductivity of $0.14-0.28 \mathrm{Kcal} / \mathrm{mh}{ }^{\circ} \mathrm{C}$ and melting point of $100-260{ }^{\circ} \mathrm{C}$. The sawdust particles were $20-60$ mesh, placed in a laboratory electric oven at $103^{\circ} \mathrm{C}$ for 3 hours to reach $1 \%$ moisture content and then kept in the plastic bags until the production of test boards.

\section{Manufacturing of test boards}

The test boards were made with the mixing ratio of sawdust particles and PVC waste of 50:50\%, 45:55\%, 40:60\% and press time of $8,10,12$ minutes. Board density $\left(1 \mathrm{~g} / \mathrm{cm}^{3}\right)$, board thickness $1 \mathrm{~cm}$, press temperature $180^{\circ} \mathrm{C}$, press pressure 20 bar was constant for all treatments. The homogeneous mixture of sawdust and PVC waste was poured carefully by hand into a $20 \times 20 \times 1 \mathrm{~cm}$ metal mold. The formed mat was hot pressed at a temperature of $180{ }^{\circ} \mathrm{C}$ and a pressure of 20 bar. After hot pressing, panels were kept in a cold press for 5 minutes and then placed in a room conditions (temperature of $20^{\circ} \mathrm{C}$ and relative humidity $65 \%$ ) for 2 weeks. The test panels were cut in samples to determine their physical and mechanical properties.

\section{Experimental}

The bending strength were determined according to ASTM D-790 standard, tensile strength according to ASTM D-638 standard, by Instron4486 device and impact strength according to ASTM D-256 standard, by the SILT20D Santam device. Thickness swirling in 24 hours immersion in water was determined according to ASTM D1037 standard.

\section{Statistical analysis of data}

This study was conducted in the form of a completely randomized design and factorial test. The variance analysis of the interaction effects of the variable factors on the characteristics of boards was done at $1 \%$ significance level.

\section{Results and Discussion}

Statistical analysis of the results showed that the density of the test boards of various treatments

was not significantly different.

\section{Effect of mixing sawdust and PVC}

Thickness swelling: The results showed that ratio of sawdust / PVC had significant effect on the thickness swelling.

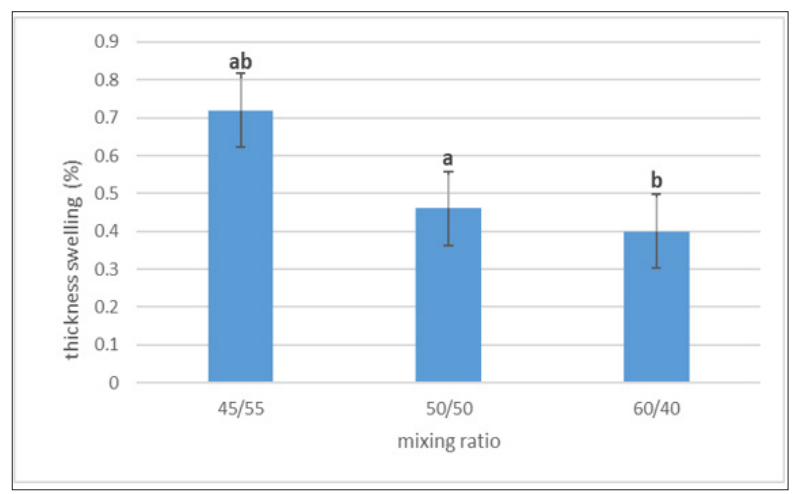

Figure 1: Effect of different mixing ratio on thickness swelling. 
As shown in Figures 1 \& 2, the lowest thickness swelling is in composites panels produced using mixing ratio of 60:40, and had a significant difference with those of 50:50 ratio. All formulations reached their maximum thickness swelling after almost 100 hours. Tajvidi et al. [2] also found that by increasing the amount of PVC, the thickness swelling of panels decreases, which is resulting from the reducing the amount of hydrophilic sawdust in the structure of composites panels.

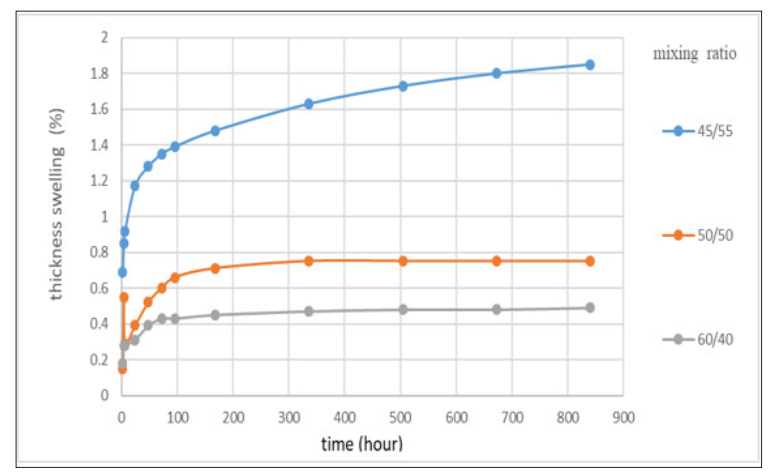

Figure 2: Effect of different mixing ratio on longterm thickness swelling.

Mechanical properties: The effect of mixing ratio of sawdust and PVC wastes on the bending strength, tensile strength and impact strength, bending and tensile modulus of the panels is presented in Figures 3-5. Statistical analysis has showed that the change in results is significant only for bending and tensile modulus.

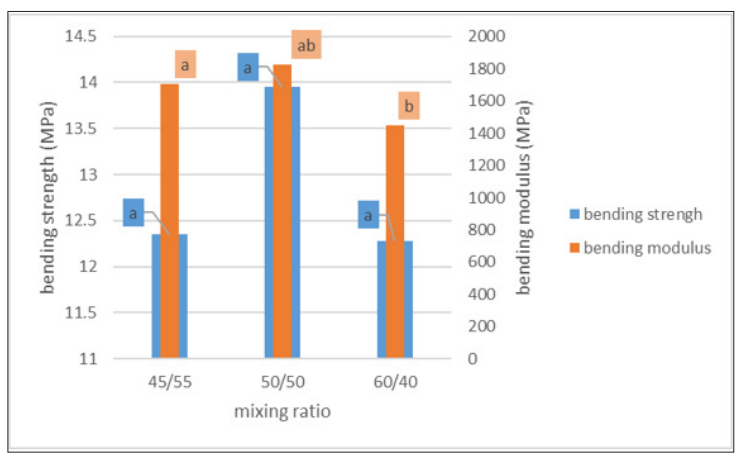

Figure 3: Effect of mixing ratio on the bending strength and bending modulus.

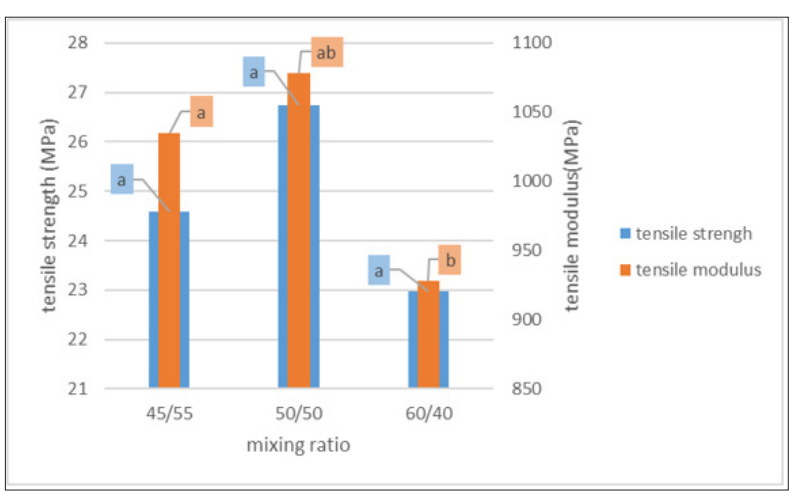

Figure 4: Effect of mixing ratio on tensile strength and tensile modulus.

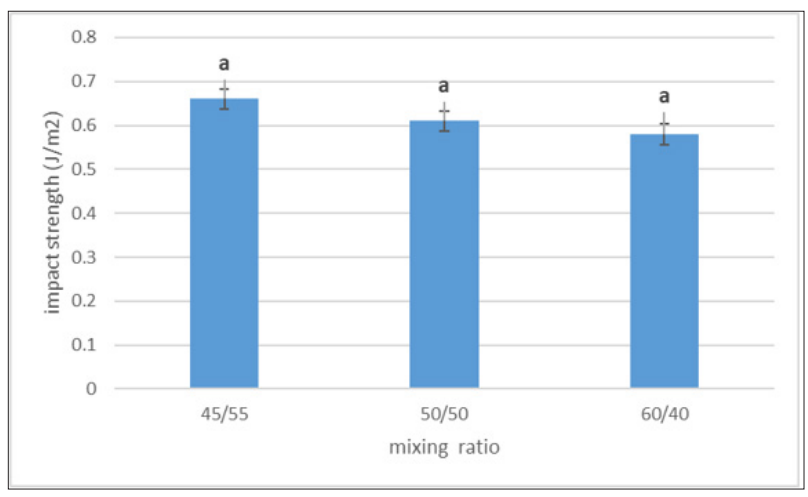

Figure 5: Effect of mixing ratio on the impact strength.

The maximum bending strength was for the composite panels produced using mixing ratio of 50:50 (Figure 3). Munoz [12] also concluded that increasing fiber content up to $55 \%$ in the mixture, increases the bending strength of composite. Very fine fibers obtained from MDF wastes provide a high specific surface. Higher aspect ratios provided better transfer of stress to the particles in the matrix, resulting in a higher MOR. MOE data indicated that the maximum bending modulus is for a composite panels made using a mixing ratio of 50:50 (Figure 3). Ziaei et al. [13] also reported that increasing the percentage of lignocelluloses filler mixed with Heavy Polyethylene (HDPE) up to 50:50 increases bending modulus of the composite panels. This increase in MOE values can be also contributed to the better transfer of stress to the fibers, due to their higher aspect ratios.

Tensile strength was also relatively improved as PVC content increased and reached its maximum by $50 \%$, then showed a decreasing trend (Figure 4). Statistical analysis revealed no significant difference in all PVC/sawdust mixing ratios. The same increasing trend was reported by Munoz [12]. This increase in tensile strength values can be also contributed to the better transfer of stress to the flax fibers, due to their higher resistance against tensile stress. In addition, results showed an increasing trend in MOE as PVC/sawdust ratio increased to 50:50 and reached its maximum value and then reduced (Figure 4). It is hypothesized that fine wood fiber had better integration with the plastic matrix [13].

Impact strength represents the resistance of materials against crack initiation. The more value is, the more energy the specimen absorbs. Impact resistance tests showed higher value when the sawdust content in test panels was 55 percent (Figure 5). Statistical analysis revealed no significant difference in all PVC/sawdust ratios. Rangavar et al. [14] reported the same increasing trend in the evaluation of properties of composites panels produced using PVC and wood powder.

\section{The effect of press time}

Thickness swelling: The results of thickness swelling showed that as the press time increased, the amount of thickness swelling decreased (Figures $6 \& 7$ ). The lowest thickness swelling was for WPC panels made in press time of 12 minutes. This explains that 
PVC matrix had enough time to cover the whole sawdust particles, this allows the reduction of surface of moisture sorption and decreased the thickness swelling of panels.

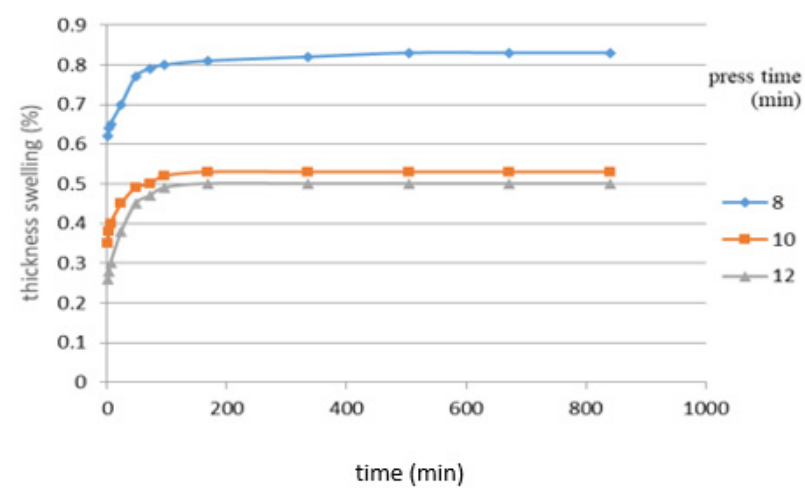

Figure 6: Effect of press time on the composite thickness swelling.

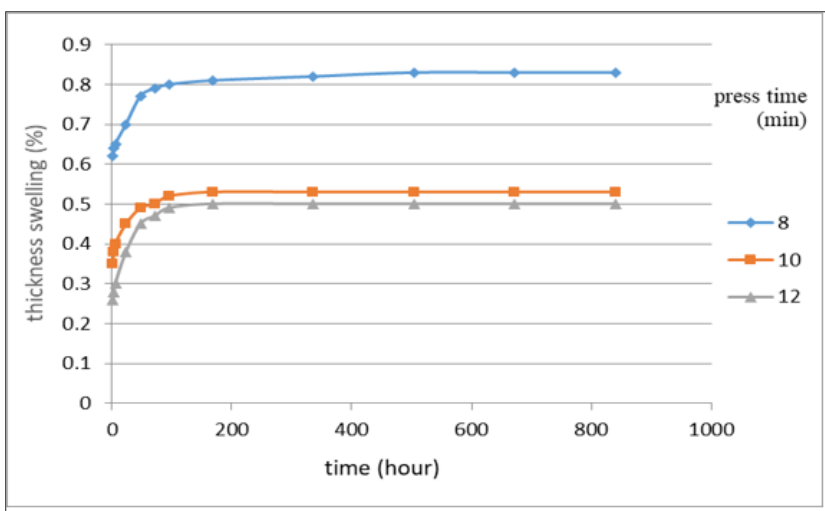

Figure 7: Effect of press time on long-term thickness swelling.

Mechanical properties: The effect of press time on all mechanical properties excluding impact resistance and tensile modulus was significant.

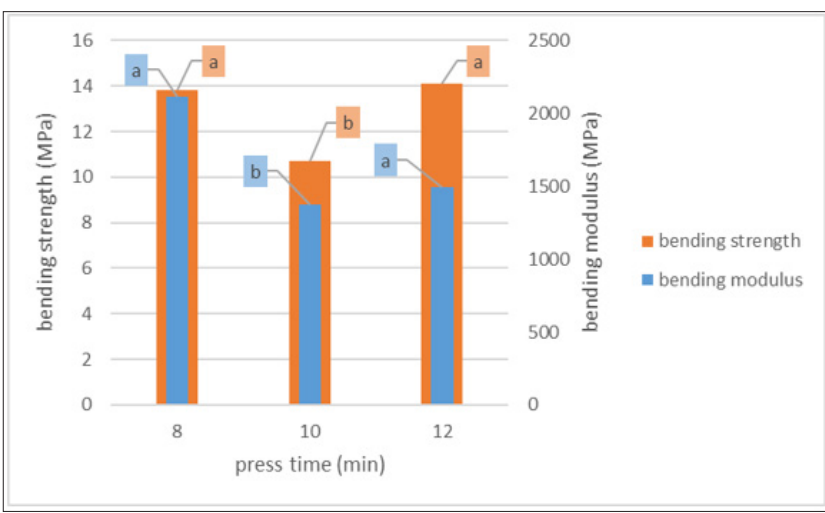

Figure 8: Effect of press times on the bending strength and bending modulus.

Results of bending strength tests indicated a decrease when the press time was increased up to 10 minutes and then showed an increasing trend (Figure 8). The maximum bending strength was for WPC made in press time of 8 minutes with. Increase in MOR as a result of increase in press time was also reported in other studies [15]. Higher press time provided better material distribution during hot pressing and therefore better transfer of stress to the sawdust particles in the matrix. The highest bending modulus was also obtained for composite panels made in press time of 8 minutes (Figure 8). Rangavar et al. [14] suggest that the unusual behavior of PVC in the wood-plastic composite could be caused by absence of thermal stabilizers. Therefore, reducing the bending modulus of panel for press time of 10 minutes can be related to the nature of PVC.

The maximum tensile strength was for WPC made in 12 minutes, but there is no significant difference with those produced in 8 minutes (Figure 9). The results indicate that the tensile strength of the composite decreased when the press time increased up to 10 minutes [16]. Absence of thermal stabilizers can be caused unusual behavior of PVC during the hot pressing. Although no significant, the results of tensile modulus data showed that the maximum tensile modulus was for a composite panels made in press time of 8 minutes (Figure 9). The tensile modulus reduced as a result of increase the press time up to 10 minutes and then showed an increasing trend when the press time increased.

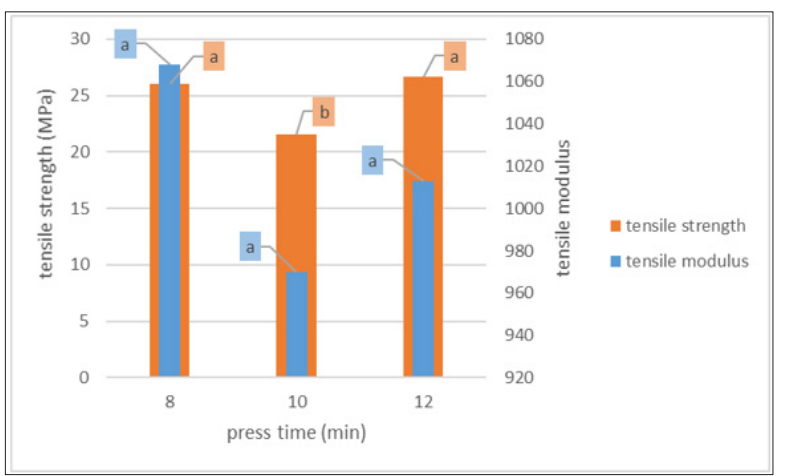

Figure 9: Effect of press times on tensile strength and tensile modulus.

The impact strength was also improved as the press time increased to 10 minutes and then showed a decreasing trend (Figure 10). Statistical analysis revealed no significant relationship between the press time and impact strength of panels. The maximum impact strength was for composite made in press time of 10 minutes. Matie et al. [15] also reported similar trend.

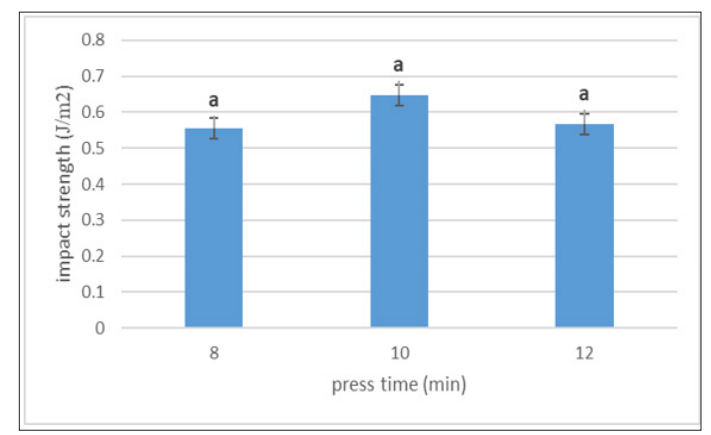

Figure 10: Effect of press times on the impact strength. 


\section{Conclusion}

Based on the results it may be concluded that the PVC/Sawdust ratio greatly affect the physical and mechanical properties of WPC. The mechanical properties of panels were significantly higher when the PVC/Sawdust ratio of 50:50 was used. Thicknesses swelling in 24 hours as well as in long term both decreased with the increase in PVC / sawdust ratios. In addition, the physical and mechanical properties of composite have been significantly affected by press time. Although no specific relationship was found between the press time and physical and mechanical properties of composites.

Moreover, it was found that the panel made of 50\% PVC combined with 50\% sawdust pressed for 8 minutes exhibited overall suitable properties for most applications.

\section{Acknowledgment}

The authors would like to acknowledge the financial support of the Iran National Science Foundation (INSF).

\section{References}

1. Tasouji M, Noorbakhsh A, Kargarfard A, Hosseinkhani H (2012) Effect of type of lignosullose and nanores on the physical, mechanical and morphological properties of polystyrene wood. Iranian Journal of Wood and Paper Science Research 27(2): 201-189.

2. Tajvidi M, Haghdan S, Kazemi (2008) Physical properties of novel layered composites of wood flour and PVC. Journal of Reinforced Plastics and Composites 27(16-17): 1759-1765.

3. Kargar Fard A, Nourbakhsh A (2015) Possibility of using soybean stem flour in polypropylene wood-plastic polystyrene. Scientific-Research Quarterly Journal of Iranian Wood and Paper Science Research 30(3): 442-430.

4. Nourbakhsh A (2012) Comparison of four lignosullose materials in the production of polystyrene/nanoclay polystyrene. Scientific-Research Quarterly Journal of Iranian Wood and Paper Science Research 27(2): 235-255.

5. Aliyegbenoma CO, Apkobi JA, Olodu DD (2019) Modelling and production of injection moulded polyvinylchloride-sawdust composite. J Appl Sci Environ Manage 23(12): 2159-2164.
6. Ahmad Shubbar S (2013) Injection temperature effects on the properties of high density polyethylene crate. Journal of Engineering 19(6): 752763.

7. Wechsler A, Hiziroglu S, Ballerini A (2008) Proceedings of the $51^{\text {st }}$ International Convention of Society of Wood Science and Technology. Pp. 1-10.

8. Chaharmahal M, Kazemi Najafi S, Tajwidi M (2006) The effect of the type of construction method on the mechanical properties of plastic wood boards made of wood particle board waste. Two Quarterly Journal of Iranian Wood and Paper Science Research 21(1): 42-33.

9. Ghasemi A, Azizi H, Ehsani Namin P (2008) Investigating the effect of wood particle size on the rheology and physical-mechanical properties of wood-polypropylene composite. Journal of Polymer Science and Technology 21(93): 45-52.

10. Shakeri A, R Silani L, Omidvar A (2002) Investigate the composition of cellulose-polymer composite products using recycled polystyrene and waste newspaper paper. Iranian Journal of Natural Resources 55(3): 407-417.

11. Stark NM, Rowlands RE (2003) Effects of wood fiber characteristics on mechanical properties of wood/polypropylene composites. Wood and Fiber Science 35(2): 167-174.

12. Muñoz E, García-Manrique JA (2015) Water absorption behaviour and its effect on the mechanical properties of flax fibre reinforced bioepoxy composites. International Journal of Polymer Science, Pp. 1-110.

13.Ziaei Khosroshahi S, Mahdinia M, Enayati AA (2015) A comparative study of the physical and mechanical properties of multilayer plastic wood made of different lignosullose materials and heavy polyethylene. Journal of Wood and Forest Science and Technology Research 22(1): 7592.

14. Rangavar H, Urmia A, Safarpour A, Gholipour T (2013) Investigation of the use of recycled polyvinyl chloride (PVC) in the manufacture of woodplastic multilayers. Scientific-Research Quarterly Journal of Iranian Wood and Paper Science Research 28(1): 35-47.

15. Motiee N, Ebrahimi Gh, Tajvidi M, Layeghi M (2014) Minimizing hotpress time in the manufacturing process of wood plastic composites. Iranian Journal of Wood and Paper Industries 4(2): 79-90.

16. Nourbakhsh A (2015) Potential for the use of agricultural and mineral fiber wastes in the manufacture of multi-purpose plastic wood. Scientific-Research Quarterly Journal of Iranian Wood and Paper Science Research 30(2): 220-229. 